\title{
Perfil de sono e ansiedade em atletas de futsal com Síndrome de Down no período competitivo.
}

Diego Silva Mota*, Nádia Esteves dos Santos, Cleber de Oliveira Silva, Rodrigo Campos Rodrigues, Profa. Dra. Marta Fuentes Rojas, Profa Dra Andrea Maculano Esteves.

\section{Resumo}

A síndrome de down (SD) é uma deficiência cognitiva caracterizada por um erro na distribuição cromossômica durante a divisão celular do embrião. O incentivo e a prática de futsal por pessoas com SD tem crescido no Brasil, levando a aderência ao treinamento de alto rendimento e a criação de competições a nível estadual, nacional e mundial. A má qualidade de sono, obesidade e ansiedade pré competitiva excessiva podem ser prejudiciais para a performance esportiva. No entanto, pelo futsal down ser uma modalidade nova, pouco se tem na literatura sobre atletas com SD. O objetivo deste estudo foi avaliar o sono, antropometria e ansiedade em atletas de futsal com SD no período competitivo. Foram avaliados 7 atletas de futsal, com idade média de 28,4, no campeonato nacional. Questionários sobre sono, ansiedade-traço e ansiedade-estado competitiva foram aplicados no momento basal e competitivo (antes dos 4 jogos). Os achados sugerem que o perfil antropométrico, sono e ansiedade são característicos da população com SD e durante o período competitivo as alterações negativas na qualidade do sono podem ser potencializadas.

\section{Palavras-chave:}

Futsal Down, Sono, Síndrome de Down.

\section{Introdução}

A síndrome de down (SD) é uma deficiência cognitiva caracterizada por um erro na distribuição cromossômica durante a divisão celular do embrião. Por razões morfofisiológicas, uma elevada incidência de pessoas com SD apresenta obesidade, distúrbios do sono e risco de doenças cardiovasculares ${ }^{1}$, sendo a prática de exercício físico, esportes, hábitos alimentares e a participação social, potenciais reversores desse quadro². A prática de esportes competitivos dentre o público com SD está crescendo e, dentre as modalidades que estão ganhando força, encontra-se o futsal Down. Em 2018, ocorreu o $1^{\circ}$ Campeonato Brasileiro de Futsal Down (FD) reconhecido pela Confederação Brasileira de Desportos para Deficientes Intelectuais (CBDI). A má qualidade de sono, sobrepeso e ansiedade competitiva excessiva podem influenciar negativamente 0 desempenho esportivo, podendo culminar em lesões e má recuperação ${ }^{3}$. No entanto, não se conhece esses fatores em atletas de FD. Assim, o objetivo desse estudo foi avaliar o perfil de sono e ansiedade em atletas de futsal com SD no momento basal e competitivo (em 4 partidas).

\section{Resultados e Discussão}

As variáveis sobre sono foram avaliadas através dos questionários Epworth, Horne \& Ostberg (Cronotipo), Berlin (Apneia obstrutiva do sono - AOS) e o mini questionário do sono (MQS). A ansiedade-traço foi avaliada através do Sport Competition Anxiety Test-C (SCAT-C) e a ansiedade-estado através do Competitive State Anxiety Inventory-2R (CSAI-2R).

Tabela 1. Média da equipe no momento basal:

\begin{tabular}{ccccccc}
\hline Idade & Peso & Altura & IMC & CC & CQ & RCQ \\
\hline 28,4 & 77,3 & 1,53 & 33,18 & 101,3 & 105,9 & 0,95 \\
\hline \%G & Cronotipo & Epworth & MQS & AOS & SCAT-C \\
\hline 35,4 & 54,86 & 9,14 & 26,43 & 3 atletas & 35 \\
\hline
\end{tabular}

A equipe apresentou obesidade grau I (IMC $=30-34,9)$, circunferências e perceptual de gordura elevados, além de enquadrarem no grupo de risco para comorbidades cardiovasculares $(R C Q \geq 0,9)$. A equipe apresentou sono levemente alterado (MSQ $=25-27)$, apresentaram sonolência diurna excessiva (Epworth $\geq 9$ ) e $43 \%$ apresentaram apneia obstrutiva do sono. Em relação a ansiedade-traço competitiva, apresentaram alta ansiedade (SCAT-C $\geq 28$ ).

Gráfico 1. Ansiedade-estado competitiva, sonolência e qualidade do sono no período competitivo:

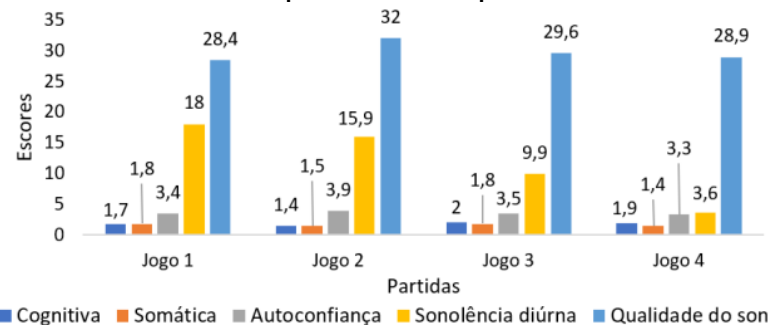

A equipe apresentou "sono muito alterado" no dia do segundo jogo (>30) e "moderadamente alterado" nos demais dias (28-30), a sonolência reduziu ao decorrer dos dias de jogos, apresentando sonolência excessiva diurna nos dias de jogos 1,2 e 3 . A equipe apresentou autoconfiança em todas as partidas $(\geq 3)$, ansiedade cognitiva no dia do terceiro jogo após derrota na partida anterior ( $\geq 2$ ) e não apresentaram ansiedade somática.

\section{Conclusões}

Os achados sugerem que a equipe apresenta perfil antropométrico, de sono e ansiedade-traço competitiva alterados, indo ao encontro dos achados na literatura. No período competitivo, as alterações na qualidade sono pode ser negativamente potencializadas e, mesmo em competição, os atletas com síndrome de down apresentaram muita autoconfiança em todos os jogos.

\section{Agradecimentos}

Laboratório de Sono e Exercício Físico, Associação de Reabilitação Infantil Limeirense, SAE, CNPq e CAPES.

\footnotetext{
${ }^{1}$ Horne, R. S.; Wijayaratne, P.; Nixon, G. M. e Walter, L. M. Sleep medicine reviews, 2018, 44, 1-11.

${ }^{2}$ Churchill, S. S.; Kieckhefer, G. M.; Bjornson, K. F. e Herting, J. R. Sleep, 2015, 38, 61-71.

${ }^{3}$ Watson, A. M. Current sports medicine reports, 2017, 16(6), 413-418.
} 